\title{
The Design Towards a News Aggregator Subscription Service: Results from an Online Experiment
}

\author{
Erol Kazan \\ IT University of Copenhagen \\ erka@itu.dk
}

\author{
Tuure Tuunanen \\ University of Jyväskylä \\ tuure@tuunanen.fi \\ Mengcheng Li \\ University of Jyväskylä \\ mengcheng.m.li@jyu.fi
}

\author{
Hadi Ghanbari \\ Aalto University \\ hadi.ghanbari@aalto.fi
}

\begin{abstract}
The newspaper industry is on a quest to discover sustainable business models. Digital subscriptions are stable revenue generators for most publishers. That being said, smaller publishers face challenges. By not having the same resource base to offset costs compared to larger ones, small publishers are in a constant state of financial unpredictability. Another persistent problem among them is the high churn rate of subscriptions (i.e., the cancelation rate), which suggests a value misalignment between readers and service. New services like news aggregators may promise publishers a large pool of paying readers, as readers have access to diverse content by different publishers and are willing to pay for pooled news content. But platform fees and the disintermediation of direct customer relationships enact barriers for many publishers. To address these shortcomings, this study conducts an online experiment based on design science research to test the performance of different payment plans for a collaborative news aggregator service. We identify preliminary design principles for value creation and capture, which can be utilized for designing a commercial and collaborative news aggregator service.
\end{abstract}

\section{Introduction}

Newspapers are vital institutions in societies as they create public discourse to hold stakeholders accountable and inform citizens. To fulfill their tasks in the digital age, publishers expanded their distribution channels to the digital realm to serve online readers. In so doing, many publishers, however, are challenged with their digital subscription models. While printed newspapers continue to be a reliable revenue generator, early signs indicate stagnation and, for some publishers, a decline in their growth trajectories. Thanks to ubiquitous computing, online channels gained importance in monetizing online content. The importance is also reflected by investments in digital units to leverage on these growth opportunities. That being said, revenues from online newspapers have become increasingly unpredictable. With the rise of ad blockers, privacy awareness among readers, restrictive mobile platforms with regards to data collection (e.g., Apple), and competition with public broadcasters and global content platforms (e.g., Facebook, Google), publishers are surrounded by new and old rivals for the same users and advertisement spending. To become financially more independent, publishers increasingly rely on digital subscriptions.

Although digital subscriptions promise stable revenues, and resourceful publishers with global coverage have indeed benefited from it (e.g., New York Times), smaller publishers (e.g., local newspapers), continue to struggle in increasing their subscription numbers [1]. To illustrate, smaller publishers have difficulties in convincing readers to pay for digital subscriptions in the first place [28], as users have, in most cases, a limited budget for media spending, while similar content is freely available just few clicks away. Secondly, even if readers start to pay for digital subscriptions, the churn rate, which is the rate of cancelations, is considerably high, which suggests a value mismatch between paying users, price, and content [28],. Based on these observations, this problem presents an opportunity for improvement.

Platform organizations (e.g., Apple) recognized the problem and started to offer news aggregator services (Apple News+), which pool content by different publishers in one service. Many publishers, however, are skeptical due to fears of being commoditized and losing control over content distribution, customer relationships, and monetization options [2]. If we consider the prevailing trend of aggregated services in different media industries, like music (e.g., Spotify), books (e.g., Amazon Kindle), movies (e.g., Netflix), and now in the newspaper industry (e.g., Apple News + , Blendle), questions arise as to how to design a news aggregator service, and at the same time, address the concerns of newspaper 
publishers. A significant concern is the dependence on a single actor who has monopolistic power over such a service, such as Apple or Amazon [2]. A collaborative or consortium-based solution, on the other hand, could potentially alleviate some of the concerns as control and risk are shared among participating publishers. This type of organizational arrangement could take the form of a strategic alliance, consortium, or inter-organizational platform service [3].

As this kind of service has its potential, we lack knowledge as to how to design a collaborative news aggregator service in the first place. While prior research provided valuable insights about various commercialization efforts in the newspaper industry (e.g., paywalls, freemium business models, the role of news apps) [4-7], how a shared business model for a news aggregator service could look like has remained elusive so far due to its novelty. A subscription service that is co-owned by multiple competing publishers is arguably different compared to existing monopolistically controlled news aggregators, which, in turn, is subject to various governance, business, and technology needs.

To understand favorable conditions, this research conducts an online experiment to derive preliminary insights and design principles to utilize them for future studies with newspaper stakeholders in Finland. The goal of this study is to support a larger design science research (DSR) [8-10] study that seeks to identify and evaluate design principles for a collaborative news aggregator service that is operated by different publishers [28]. To the best of our knowledge, we are not aware of any public news aggregator services that are operated collaboratively by competing publishers.

To explore favorable collaboration conditions, this study developed a software artifact that imitates a news aggregator service with authentic news content by various newspaper publishers. Furthermore, we leverage on Amazon Turk workers to test the performance of three market-orientated news subscription payment plans. With the gained findings, our goal is to probe newspaper stakeholders to solicit tension points (e.g., business and technology tension points) and pinpoint conditions that support collaboration. In this line, this study is explorative in its nature and proposes the following research question: How do different payment plans perform for a news aggregator service?

To answer the research question, we provide theoretical background on strategic alliance and business model literature, and conduct an online experiment to study the performance of three marketorientated payment plans and user behavior $[3,11]$. This study contributes to the aforementioned research streams and specifically to the area of online experiment studies targeting online newspaper subscriptions. From a practitioner viewpoint, this study could have significant implications for the Finnish newspaper industry by presenting a competitive alternative solution to monopolistic news aggregator services. From a societal viewpoint, this kind of service may assist in having better-informed citizens.

\section{Theoretical Background}

\section{Newspaper Studies}

Scholars studied the newspaper industry through various theoretical lenses. Studies tried to unpack the open innovation dynamics in the Danish and Swedish newspaper industries [12, 13], understanding the merger implications between newspapers (e.g., price) [14], treating newspapers as multi-sided platforms to attract different stakeholders [15], how publishers leverage on dynamic capabilities during industry transformation [16], or how online publishers become more entrepreneurial in their operations with new content delivery and business models [5, 17]. A more recent study in Norway suggests that local newspapers with content paywalls struggle with their monetization efforts. The study indicates a value misalignment between content and reader perceptions; While elderly readers continue to be loyal print subscribers, their use of digital channels, which is complementary to their existing print subscriptions, is negligible in their adoption. Furthermore, results suggest that particularly younger and low-income readers reject paywalled local content and prefer to consume alternative and freely accessible news, which may contribute to less informed local citizens [1].

Overall, existing newspaper studies provide rich insights about publishers embedded in different theoretical environments or shed light on their commercial efforts. Although newspaper publishers are fierce competitors between each other, many publishers collaborate in many ways and degrees (e.g., content licensing, regulations on user data). These collaborations, though, are predominately noncompetitive in their attributes. A collaborative news aggregator service, on the other hand, where content is in the vicinity to competitors is an unexplored area. With the recent rise of news aggregators services that are monopolistically controlled (e.g., Apple News + ), it suggests a rethinking of the current status quo how publishers could monetize their news content. One steppingstone to this change is through commercial collaborations, which is synonymous with strategic alliances. 


\section{Strategic Alliance}

Organizational competition in network economies is increasingly driven by strategic alliances, where multiple organizations pool resources to co-create demanded products and services. In the strategic management literature, these types of organizational arrangements are similar to coopetition or strategic alliances [3, 18], where competitors pool select resources and capabilities to achieve mutual benefits such as economy of scale and scope. Strategic alliances are difficult to create or imitate as they are outcomes of complex managerial negotiations [3]. In

the same vein, the ability to enter an alliance is unevenly distributed, as the value of specific resources is perceived to be tradeable, weakening the position of alliance seekers [3].

Considering competitiveness in digital industries (e.g., social media, payments), organizations are deemed to be competitive, if they have a large userbase, high market reach, or can attract select partners to their business network [19]. If digital organizations are not sufficiently equipped for competition, literature suggests strategic alliances as a mean to compensate for organizational shortcomings. Thus, organizations lacking industryspecific resources may join strategic alliances to compensate for their deficiencies. From a different perspective, if the costs of belonging to a strategic alliance outweigh individual benefits, members are inclined to reduce their involvement, which in turn may reduce the overall effectiveness of a strategic alliance. One motivation to leave a strategic alliance is the desire to regain organizational flexibility and control over their value creation and capture process. In other words, their business model.

\section{Digital Business Models}

Research on business models have received considerable attention among scholars to explain the logic of how organizations create and capture value [11, 20-24]. In the newspaper industry context, business model studies explored how credibility impacts a publisher's monetization efforts [4], how mobile apps support the decrease of churn rates [7], unpacking the conversation rate between freemium business models [6], or how studies dissect the relationship between free and paid news articles [5, 25]. The aforementioned studies provide valuable business model insights pertinent to online media publishers. Though, we lack understanding as to how to design and align a business model in a collaborative setup, as proposed in this study.

Generally speaking, digital business models consists of four generic dimensions: (1) value creation (e.g., product or service offer); (2) value capture (e.g., pricing); (3) value architecture (e.g., platform); and lastly (4) value network (e.g., stakeholders). Table 1 contextualizes the four generic digital business model dimensions in the online newspaper context. Arguably, the first two digital business model dimensions are subject to a quantitative research approach, as to how certain payment plans perform (e.g., online experiment). The two-remainder, on the other hand, share the attributes of being strategic and tactical, suggesting a qualitative approach (e.g., interviews) to illuminate collaboration conditions between newspaper publishers.

Table 1. Business model dimensions

\begin{tabular}{|l|l|l|}
$\begin{array}{c}\text { Value } \\
\text { Dimensions }\end{array}$ & $\begin{array}{c}\text { Newspaper } \\
\text { Subscription }\end{array}$ & Value Principles \\
\hline Creation & News Articles & $\begin{array}{l}\text { Attractive } \\
\text { Content }\end{array}$ \\
\hline Capture & Payment Plan & $\begin{array}{l}\text { Competitive } \\
\text { Pricing }\end{array}$ \\
\hline Architecture & $\begin{array}{l}\text { Digital } \\
\text { Platform }\end{array}$ & $\begin{array}{l}\text { An effective } \\
\text { content delivery } \\
\text { architecture }\end{array}$ \\
\hline Network & Publishers & $\begin{array}{l}\text { A select business } \\
\text { network }\end{array}$ \\
\hline
\end{tabular}

To answer our research question, in this study we focus predominantly on evaluating the first two business model dimensions by conducting an online experiment.

\section{Research Design}

Our research design needs to reflect the involvement of practice to deliver a particular solution to an existing problem. In this study, our proposed solution takes the form of a news aggregator service that is collaboratively operated by competing newspaper publishers. In this line, we take a DSR approach [8] and more specifically apply DSR methodology [10] to conduct our study, which is a well-established method of inquiry in information systems research [9]. DSR methodology [10] builds on DSR process models and proposes a structured process to conduct DSR. It is comprised of six phases: (1) identify the problem and motivation; (2) define the objectives; (3) design; (4) demonstrate; (5) evaluate; and (6) communicate [10].

To gain preliminary insights about the barriers and common grounds for a collaborative newspaper subscription service, we initially conducted semistructured interviews with the representatives of four 


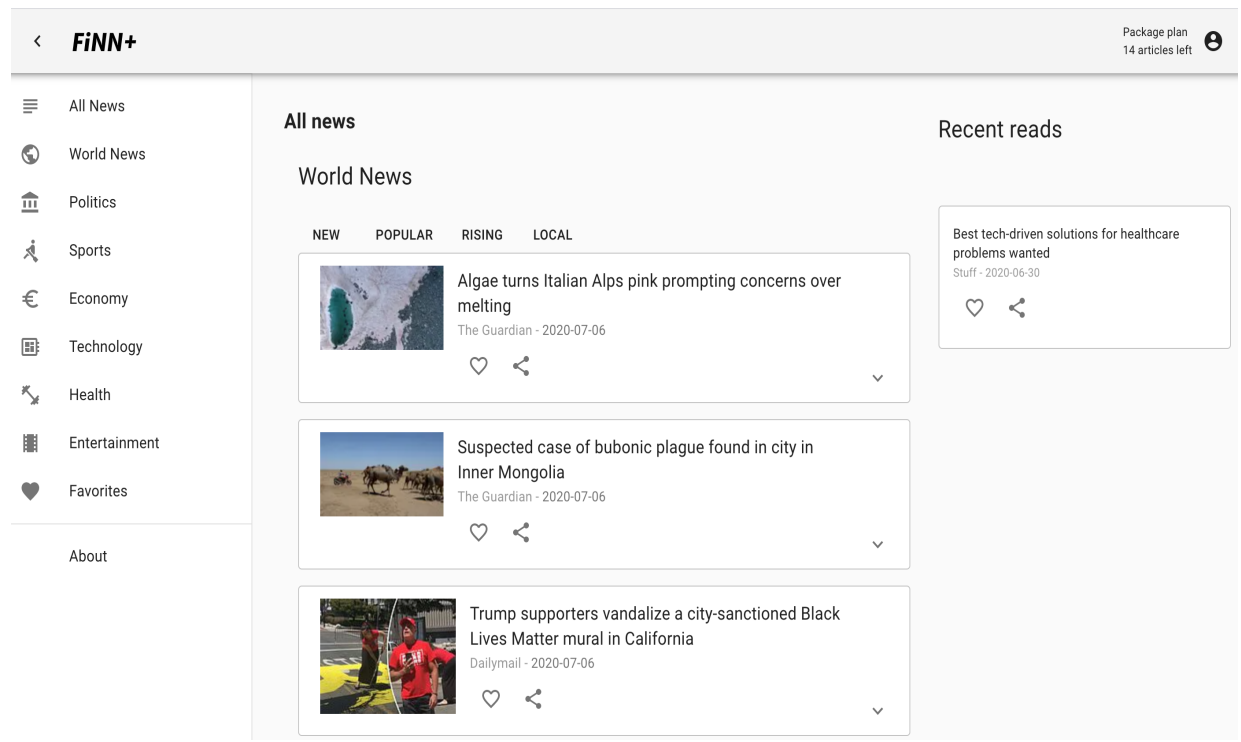

Figure 1. Artifact dashboard

industry association [28]. Subsequently, the research team studied various newspaper subscriptions and aggregator services to gain a better understanding of accessing and reading news articles. Based on these insights and having several rounds of discussions with different industry stakeholders and with the academic community, the research project developed iteratively a software artifact that resembles a news aggregator service that sources content from various (English speaking) newspaper publishers. The artifact is designed in such a way as it automatically crawls freely accessible news content via the Really Simple Syndication protocol (i.e., RSS), and displays them in a modified form (i.e., add-free) 1) as a continues stream of news, and 2) categorizes them based on content type such as sports, politics, etc. (see Figure 1). As such, the content hosted on the artifact presents authentic news content.

This present study is a continuation of the abovementioned research project from a user viewpoint by conducting an online experiment. By measuring the performance of the proposed software artifact in terms of usage (e.g., number of read articles), and different payment plans, the goal is to leverage on these insights to assist future studies that further seek to evaluate the designed artifact and the underlying design principles [28]. Specifically, the insights from the online experiment will be integrated into follow up studies to probe newspaper stakeholders to solicit their opinions and obtain statements towards engaging in a strategic alliance for a new type of news subscription service.

Online Experiment. To test the performance of our proposed software artifact, we conducted an online a set of questions to be answered by testers. Next, we recruited 32 testers (age group 25-35) through Amazon Turk.

At the beginning of the online experiment, the software artifact requires from the Amazon Turk workers to select one of the following three marketorientated payment plans:

- Single Plan (\$0.50): Each article costs $\$ 0.50$

- Package Plan (\$6.45): Users can read up to 15 articles

- Monthly Plan (\$9.50): Users can read as many articles as they want.

Inspired by prior marketing studies on pricing experiments (i.e., usage versus unlimited pricing) [26, 27], we designed the payment plans to reflect existing market prices for monthly newspaper subscriptions or news providers, which supported single article payments (e.g., Blendle). The design of the "Package Plan," on the other hand, is based on our research findings.

Concerning the latter, we conducted a workshop with Finnish newspaper publishers to solicit opinions related to the proposed software artifact. A common understanding was established among workshop attendees that a hybrid subscription solution (i.e., package plan) bundled with existing newspaper subscriptions could present a viable solution, which does not cannibalize existing newspaper subscriptions. Furthermore, it was suggested that this type of subscription model provides exposure to new readers. In this line, we integrated the package model, labeled as a hybrid solution, as part of our online experiment. 
We designed our online experiment with the following worker instructions:

To test the FiNN+ user experience, please summarize a minimum of 5 news articles but not more than 10. One paragraph of a summary is sufficient. We check the truthfulness and quality of your summary. You have an imaginary total budget of $\$ 15$ at your disposal, and you are free to choose any of the payment plans to get the task done [...]. Your compensation is as follows:

- For each accepted news article summary, we
We carefully designed the imaginary budget (i.e., $\$ 15$ ), payment plans (i.e., single, package, and monthly plans), and the worker compensation in such a way that the maximum compensation for workers is always $\$ 10$, no matter which payment plan has been chosen or the number of read articles (i.e., reader compensation). In so doing, our goal was to deter workers in gaming the online experiment to their economic benefit, determine their value perception, and individual estimation about their expected use of the software artifact. In the end, our main focus was to

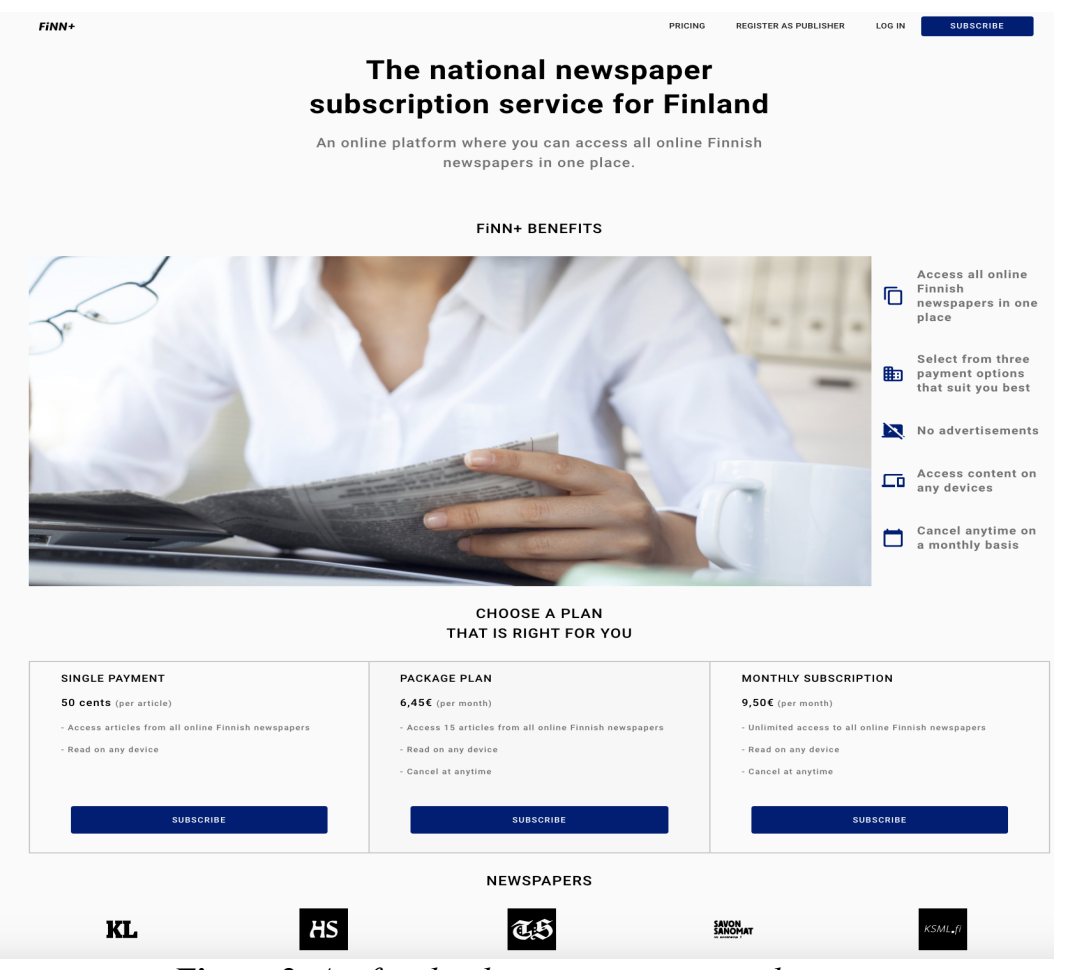

Figure 2. Artifact landing page, payment plans

pay you $\$ 1,50$.

- In addition to the summarized news articles, you get compensated for just reading additional news articles with $\$ 0.30$ each (i.e., reading compensation).

- Reading compensation is only available for the Package (maximum of 5 articles) and Monthly (maximum of 15 articles) payment plans. The Single Plan is not eligible for reading compensations.

We asked the workers to sign up for the service after familiarizing themselves with the value proposition of the service (see Figure 2). We asked the participants to choose a payment plan that is sufficient to fulfill the task above, while at the same time considering their personal budget and willingness to pay for this type of service. evaluate artifact usage and the performance of different payment plans.

\section{Evaluation Results}

After preparing and cleaning the data set (e.g., removing redundant data entries), in total, 32 Amazon Turk workers participated in the online experiment in various degrees and efforts in completing their tasks. With a total budget of $\$ 15$ at their disposal, the payment plan distribution among the 32 workers is the following:

- 16 of the workers chose the monthly payment plan that grants unlimited access to new articles,

- 12 of the workers adopted the package plan that provides access up to 15 news articles and lastly, 
- Four workers have selected the single plan, where each article costs $\$ 0.50$.

That being said, although five workers made their payment plan choices, they decided not to perform any
"Overall, I thought the platform was very nice, and I appreciated how clean and clear cut everything was. It was easy for me to navigate the site, and I found a decent amount of content that was interesting to me."

Table 2. Summary of the online experiment results

\begin{tabular}{|c|c|c|c|c|}
\hline Payment Plan & Monthly & Package & Single & Total \\
\hline Distribution & 15 & 9 & 3 & 27 \\
\hline Average Reading & $\begin{array}{c}6,6 \\
\text { articles }\end{array}$ & $\begin{array}{c}4,78 \\
\text { articles }\end{array}$ & $\begin{array}{c}5 \\
\text { articles }\end{array}$ & $\begin{array}{c}\text { articles } \\
\text { Payment Method }\end{array}$ \\
\hline $\begin{array}{c}9 \text { credit card } \\
6 \text { bank wire }\end{array}$ & $\begin{array}{c}7 \text { credit card } \\
2 \text { bank wire }\end{array}$ & 3 credit card & $\begin{array}{c}19 \text { credit card } \\
8 \text { bank wire }\end{array}$ \\
\hline
\end{tabular}

readings tasks. By removing these five workers from the data set, 27 workers were chosen, who predominately chose the monthly plan $(n=15)$, followed by the package $(n=9)$ and single plan $(n=3)$. Furthermore, we can derive the following average reading consumption across different payment plans:

- Monthly payment plan: 6,6 read articles

- Package Payment Plan: 4,78 read articles

- Single payment plan: 5 read articles

On average, all workers accessed 5,81 articles across all three payment plans. Furthermore, we collected data about their preferred payment method choice, where credit cards $(n=19)$ was the first choice, followed by bank wire $(n=8)$ (see Table 2$)$.

Besides numerical data, we also collected qualitative data from the workers, soliciting their experiences, opinions, and their payment plan choices. With regards to the overall experience, we received the following illustrative responses:

"I thought it was fantastic. there were tons of articles to choose from so I just went with what interests me like true crime and video games. they were all legitimate and well written."

"I loved it. There's a lot of valuable and important news in a lot of different categories without a lot of the trivial, unimportant things used to just fill pages that I typically have to sort through in order to get the news. It also allowed me to easily see what's happening everywhere in the world rather than just American news, something I typically don't find easy to do."

"[The] articles were varied and interesting. There were no ads or annoying pop-ups and that was fabulous."

The following value insight was derived from these responses: Diverse content by different publishers is valued within a news aggregator service. " A one-stop, ad-free platform is very appealing in my eyes, [...] Finally, the progress bar and $50 \%$ threshold for being charged is really nice, [...].

"I liked the progress bar and account confirmation at the top [...]."
This led us to form the following value insight: Simplicity in terms of navigation, usage control, and a one-stop experience are valued in a news aggregator service.

Overall, the workers understood and appreciated the value proposition of the proposed software artifact, where access to different publishers in one place was considered to be useful. Furthermore, transparency about the current usage and providing control when a reader gets charged within usage-based payment plans (e.g., package plan) was particularly highlighted as being beneficial. We also asked the workers why they chose their existing payment plans. We received comments regarding the monthly subscription:

"I wanted to be able to browse as many articles as interested me, and summarize the ones I found the most interesting but also learn more."

"I wanted the ability to briefly read any article that looked interesting, to determine if I actually wanted to read it more carefully in its entirety. I did not want to have to rely on headlines to decide what articles looked like worthwhile reads."

"I think the value of being able to read more than 15 articles a month at 6.45 is worth the price increase of about 3 dollars. I wouldn't pick the single option because I don't think a single news article is worth .50 apiece."

"I thought it was the best deal to get as many articles as I wanted for only $\$ 9.50$ a month."

"I didn't want to have to worry if I clicked one and didn't like it, didn't want to feel restrained or limited."

"The other two plans have limitations. Personally, it's hard for me to restrict myself to something. To be honest, I forgot that I don't need to read too many articles to complete the task. I thought as I'm really subscribing to a real news website. So, I didn't want to restrict myself to 15-20 articles in a month. I wanted to read as many as I want."

This is summarized as the following value insight: A payment plan that provides freedom and control in terms of content and price is valued in a news aggregator service. 
With regards to the package plan, the workers shared the following statements:

"I picked the package because 15 articles a month is sufficient for me from one news site, since I like to get my news from many different sources."

"I think being able to view and read this amount of articles was right for the project."

"If I found that I was reaching the 15-article quota, then yes. If I found I was only reading a few articles a month or wanted to read more, then I'd bump up or down."

"The payment plan which I chose meets my needs and requirements. I can read up to 15 news articles in this plan. I think this is more than enough to know about world wise news. We cannot read much articles in a month. So I think I have chosen this plan correctly."

"It seemed like a middle of the road option where I could access a good amount of content in a short period and see if I like the platform."

We summarized these responses as the following value insight: A payment plan that supports targeted and economic reading in terms of content and price is valued in a news aggregator service.

Finally, we collected comments about the single plan, which had the lowest adoption among the payment plans:

"I think I may have had plans to only read five stories. I wasn't sure if I would want to read more than five. I felt like I would be satisfied reading just five."

"Because it was the cheapest plan."

This is recapped as the following value insight: A payment plan that supports highly targeted and economic reading in terms of content and price is valued in a news aggregator service.

Based on these user feedbacks, which is summarized in Table 3, the online experiment demonstrates the feasibility of the software artifact with its different payment plans, where monthly and package payment plans were the most adopted plans in the online experiment. The single payment plan, on

Table 3. Summary of the user feedback

\begin{tabular}{|l|l|}
\hline \multicolumn{1}{|c|}{ Feedback } & \multicolumn{1}{c|}{ Value Insight(s) } \\
experience & $\begin{array}{l}\text { Diverse content from different publishers } \\
\text { is valued within a news aggregator } \\
\text { service. }\end{array}$ \\
$\begin{array}{l}\text { Simplicity in terms of navigation, usage } \\
\text { control and a one-stop experience are } \\
\text { valued in a news aggregator service. }\end{array}$ \\
\hline $\begin{array}{l}\text { Ponthly } \\
\text { Plan }\end{array}$ & $\begin{array}{l}\text { A payment plan that provides freedom } \\
\text { and control in terms of content and price } \\
\text { is valued in a news aggregator service. }\end{array}$ \\
\hline Plan & $\begin{array}{l}\text { A payment plan that supports targeted } \\
\text { and economic reading in terms of } \\
\text { content and price is valued in a news } \\
\text { aggregator service. }\end{array}$ \\
\hline Single Plan & $\begin{array}{l}\text { A payment plan that supports highly } \\
\text { targeted and economic reading in terms } \\
\text { of content and price is valued in a news } \\
\text { aggregator service. }\end{array}$ \\
\hline
\end{tabular}

the other hand, received less attention due to its restrictive reading options and exhibiting value misalignment from a price viewpoint. Lastly, the workers mentioned a few minor issues from a technical perspective, such as loading time or the grouping of content (e.g., user interface), which was not the scope of our study.

\section{Discussion}

This present study is driven by a growing urgency to improve our understanding of how to design a collaborative news aggregator service in the newspaper industry. The prevalence of news aggregator services with monopolistic governance structures such as Apple News+ have certainly their appeal for readers and certain publishers (e.g., user experience, market reach). But the newspaper industry is known for having razor-thin profit margins [1], which is particularly challenging for local newspapers, struggling with high churn rates for their subscriptions. Sharing these declining revenues with new intermediaries is for many publishers considered to be a strategic and economic risk [2].

Nevertheless, the strategic alliance literature and examples in other digital industries (e.g., payments) suggests alternative avenues that take the shape of inter-organizational arrangements $[3,18]$. This study posits there is a common ground for commercial relationships among competing publishers in the form of a news aggregator service. How such a collaborative arrangement could look like remained unexplored so far. One starting point is to experiment with subscription business models, which are value creation and capture mechanisms in its basic form.

Prior studies suggest that Finnish newspaper publishers recognized the value of a national news aggregator service, but voiced their concerns that such kind of service would be in direct competition to their existing revenue-generating subscription services [28]. That being said, the same study hypothesizes that a hybrid solution that works as an add-on on existing monthly subscription plans was considered to be a worthwhile endeavor to explore. Accordingly, this present study is a continuation of the above-mentioned study in the form of an online experiment.

We utilized the Amazon Turk service to recruit participants (i.e., workers) for our online experiment. As we instructed the workers to do specific tasks with our self-developed software artifact that resembles a news aggregator service, we aimed at evaluating the performance with regards to reading and payment plan selections (see Table 2). We were particularly interested in evaluating the feasibility of three marketorientated payment plans, with a special interest in the 
hybrid solution (i.e., package plan), as suggested in a prior study on newspapers [28].

\section{Business Model: Value Creation Dimension}

The results suggest that the service offers several benefits with regards to usability and content. Findings of the online experiment indicate that using the service was considered to be pleasant related to navigation and using newly developed features such as the payment progress bar for service information provisioning (i.e., the value of simplicity). These subsequently enabled participants to have a better feel of control in their usage, and hence, budget spending (i.e., the value of control). Lastly, most participants recognized the value proposition of the proposed news aggregator service in terms of having access to different publishers (i.e., the value of diversity).

If we apply the business model lens to derive our design principles for the value creation dimension, we can hypothesize that a news aggregator service can create value through simplicity, control, and diversity in its offering.

Understandably, the derived value creation design principles are applicable for all three payment plans. But we argue that value of control and simplicity are particularly important for usage-based payment plans (e.g., package plan), as it warrants a higher degree of control and advanced information provisioning (e.g., number of accessible articles, payment progress bar) during service use. The monthly plan presents a safe option without having the concern in being overcharged. Lastly, if a news aggregator service, or any publisher, embraces the value of control principle across different payment plans, we argue that this principle may support in reducing the churn rate of newspaper subscriptions. Readers would have the flexibility to switch payment plans that suits them the best, whether being highly economical (e.g., single plan), or recognizing the added-value of having unlimited content access (e.g., monthly plan).

\section{Business Model: Value Capture Dimension}

Monthly Plan. With regards to payment plan performance, the findings demonstrate (see Table 2) that the monthly payment plan is the most popular one. The popularity of the monthly plan was anticipated as it provides our participants the greatest freedom over content access and cost control (i.e., the value of having freedom). From a publisher's perspective, monthly plans are the most lucrative ones as they are usually premium products and accordingly priced, cost-effective in their delivery, and reliable revenue generators for a certain period of time.
We hypothesize that a news aggregator service with a monthly payment plan can capture value by providing unlimited diverse content access at the highest market price range.

Package Plan. To our surprise, the package plan performed well, which was adopted by one third among all participants. Proposed as a hybrid solution, the Amazon Turk workers conveyed the notion that the package plan was treated as a middle-of-the-road solution. The comments illustrate that the package plan was good enough to fulfill the requested task, indicating a value alignment related to limited content reading (i.e., a maximum of 15 articles) at a lower price segment (\$6.45) compared to the monthly plan (\$9.50). If we synthesize the comments among all package plan adopters, we can argue that the participants behaved strategic and anticipatory in their expected service use (i.e., the value of being anticipatory).

We hypothesize that a news aggregator service with a package payment plan can capture value when it offers its readers the ability to anticipate intermediate and diverse content access at a medium market price range.

Single Plan. We expected that the single plan would be the least adopted payment plan version due to its constraints regarding the number of accessible articles and cost. The comments among the few adopters suggest a very economic behavior concerning expected usage and spending (i.e., the value of being economical).

We hypothesize that a news aggregator service with a single payment plan can capture value when it offers minimal and diverse content access at the lowest market price range.

In summary, this study proposes various value creation and capture design principles for a news aggregator service. Considering existing monopolistic solutions (e.g., Apple News + ), most news aggregator services have opted for monthly subscription plans with unlimited content access. However, prior empirical studies insinuate that unlimited content access is not the desired option for a collaborative version [28]. To be specific, publishers voiced their concern that granting unlimited content access would be indeed valuable for readers. Though, it would diminish publishers' control over direct customer relationships.

Moreover, a news aggregator service with unlimited content access would be in direct competition to existing subscription services. Similarly, publishers have experimented with micropayments for accessing online articles in the past (i.e., single payment plans). But revenues were not viable to justify their further support. For instance, the 
Dutch news aggregator service Blendle abandoned its single payment plan introduced few years ago and started to offer solely monthly plans to remain financially sustainable.

With regard to the package payment plan, this study may have identified a new type of subscription plan that may fulfill the needs of publishers in a collaborative setup. Proposed as a middle-of-the-road or hybrid solution, this new subscription type might be more receptive towards publishers as it is complementary to their existing subscription plans. The same notion is echoed by prior studies conducted from a publisher's viewpoint [28]:

Business Development Manager: "If you are a [Publisher A] subscriber and you can then on top of that buy this [package plan], let's say 5 Euros per month than the risks are not that big for us."

Chief Digital Officer: "I think [your] comment is pretty much straight forward, close to the fact how do you package your offering [...] there might be an incremental revenue source".

Our preliminary value creation and capture design principles for a news aggregator service are summarized in Table 4.

\section{Conclusion}

This study applied DSR methodology [10] to derive design principles for a collaborative news aggregator subscription service. Leveraging on strategic alliance research, business model literature, and expanding on prior empirical studies [28], we

Table 4. Design principles for value creation \& capture

\begin{tabular}{|c|c|}
\hline $\begin{array}{c}\text { Business } \\
\text { Model } \\
\text { Dimensions }\end{array}$ & Preliminary Design Principles \\
\hline $\begin{array}{l}\text { Value } \\
\text { Creation }\end{array}$ & $\begin{array}{l}\text { Create value through simplicity, control, \& } \\
\text { diversity in your offering. }\end{array}$ \\
\hline $\begin{array}{l}\text { Value } \\
\text { Capture }\end{array}$ & $\begin{array}{l}\text { Monthly Plan. Offer a monthly plan with } \\
\text { unlimited \& diverse content access at the } \\
\text { highest market price range. } \\
\text { Package Plan. Offer a package plan that } \\
\text { provides diverse, intermediate, and } \\
\text { anticipatory content access at a medium } \\
\text { market price range. } \\
\text { Single Plan. Offer a single plan that } \\
\text { provides diverse \& economic content } \\
\text { access at the lowest market price range. }\end{array}$ \\
\hline
\end{tabular}
conducted an online experiment to test the performance of three different payment plans for the aforementioned service. The preliminary insights and derived design principles will be used to probe newspaper stakeholders to identify favorable conditions towards collaboration in the Finnish newspaper industry. Which organizational or legal form such services could take (e.g., joint venture, nonprofit) is subject to the future. That being said, other digital-based industries may serve as a source of inspiration. For instance, banks collaborate on payment promoting technologies (e.g., national payment infrastructures), while competing for customers with their own banking services. In these kinds of scenarios, simultaneous collaboration and competition (i.e., coopetition) is considered to be advantageous for participating actors, whether dominant or non-dominant actors, to ensure effective service delivery for all participating organizations at a larger scale.

This study contributes to practice and research in various ways. First, this study presents a promising avenue for deriving new knowledge for the strategic alliance literature in the form of new empirical evidence to understand the collaboration and competition logic (i.e., coopetition) in digital-based industries. Secondly, we are confident to enrich the business model literature by unpacking the value dimensions in an inter-organizational setup. This type of organizational arrangement is more complex to manage due to increased orchestration efforts across business model dimensions. Thirdly, this research contributes to the DSR literature by designing a problem-orientated solution in the form of news aggregator service and deriving digital orientated value design principles. So far, an unexplored domain in the design science literature.

From a practitioner viewpoint, this study could present a small but concrete step towards establishing a collaborative subscription service for the Finnish newspaper industry.

This study may exhibit limitations, as this research was conducted in an online experiment environment. Thus, having potentially limited applicability of our findings. In addition, the study is limited to the first two business model dimensions shown in Table 1. To study the remaining dimensions (i.e., value architecture and network), this study will provide a foundation to probe publishers for identifying favorable conditions for the remaining dimensions.

We are currently in the process of formally evaluating the developed online subscription artifact. Subsequently, circa 100-150 consumer participants will be invited to test the artifact later this year, which will assist us in collecting data on their online news consumption behavior. This will allow us to further test different pricing models, user behavior, and consequently, the performances of different business models. 


\section{References}

[1] R. K. Olsen and M. K. Solvoll, "Bouncing off the paywall-Understanding misalignments between local newspaper value propositions and audience responses," International Journal on Media Management, vol. 20, no. 3, pp. 174-192, 2018.

[2] E. Lee. "Media Companies Take a Big Gamble on Apple." The New York Times. (accessed 7th of June, 2019)

[3] R. Gulati, N. Nohria, and A. Zaheer, "Strategic networks," Strategic Management Journal, vol. 21, no. 3, pp. 203-215, 2000.

[4] B. Berger, "Commerce-oriented revenue models for content providers: an experimental study of commerciality's effect on credibility," Electronic Markets, journal article vol. 28, no. 1, pp. 93-109, February 012018.

[5] M. Fetscherin and G. Knolmayer, "Business Models for Content Delivery: An Empirical Analysis of the Newspaper and Magazine Industry," International Journal on Media Management, vol. 6, no. 1-2, pp. 4-11, 2004.

[6] O. F. Koch and A. Benlian, "The effect of free sampling strategies on freemium conversion rates," Electronic Markets, journal article vol. 27, no. 1, pp. 67-76, 2017.

[7] P. Winter and P. Alpar, "On the relationship between print and mobile channels for newspapers," Electronic Markets, vol. 28, no. 1, pp. 79-92, 2018.

[8] A. R. Hevner, S. T. March, and J. Park, "Design Research in Information Systems Research," MIS Quarterly, vol. 28, no. 1, pp. 75-105, 2004.

[9] K. Peffers, T. Tuunanen, and B. Niehaves, "Design science research genres: introduction to the special issue on exemplars and criteria for applicable design science research," European Journal of Information Systems, vol. 27, no. 2, pp. 129-139, 2018.

[10] K. Peffers, T. Tuunanen, M. Rothenberger, and S. Chatterjee, "A Design Science Research Methodology for Information Systems Research," Journal of Management Information Systems, vol. 24, no. 3, pp. 45-77, 2007.

[11] M. M. Al-Debei and D. Avison, "Developing a unified framework of the business model concept," European Journal of Information Systems, vol. 19, no. 3, pp. 359-376, 2010.

[12] C. Thorén, P. J. Ågerfalk, and M. Edenius, "Through the printing press: an account of open practices in the swedish newspaper industry," Journal of the Association for Information Systems, vol. 15, no. 11, p. 779, 2014.

[13] A. B. Holm, F. Günzel, and J. P. Ulhøi, "Openness in innovation and business models: lessons from the newspaper industry," International Journal of Technology Management, vol. 61, no. 3/4, pp. 324-348, 2013.

[14] A. Chandra and A. Collard-Wexler, "Mergers in Two-Sided Markets: An Application to the
Canadian Newspaper Industry," Journal of Economics \& Management Strategy, vol. 18, no. 4, pp. 1045-1070, 2009.

[15] D. S. Evans, "The online advertising industry: Economics, evolution, and privacy," Journal of Economic Perspectives, vol. 23, no. 3, pp. 37-60, 2009.

[16] J. Karimi and Z. Walter, "The role of dynamic capabilities in responding to digital disruption: A factor-based study of the newspaper industry," Journal of Management Information Systems, vol. 32, no. 1, pp. 39-81, 2015.

[17] J. Karimi and Z. Walter, "Corporate Entrepreneurship, Disruptive Business Model Innovation Adoption, and Its Performance: The Case of the Newspaper Industry," Long Range Planning, vol. 49, no. 3, pp. 342-360, 2016.

[18] W. Hoffmann, D. Lavie, J. J. Reuer, and A. Shipilov, "The interplay of competition and cooperation," Strategic Management Journal, vol. 39, no. 12, pp. 3033-3052, 2018.

[19] T. Eisenmann, G. Parker, and M. Van Alstyne, "Strategies for two-sided markets," Harvard Business Review, Article vol. 84, no. 10, pp. 92101, 2006.

[20] J. Magretta, "Why Business Models Matter," Harvard Business Review, Article vol. 80, no. 5, pp. 86-92, 2002.

[21] A. Osterwalder and Y. Pigneur, "Clarifying Business Models: Origins, Present, and Future of the Concept," Communications of the Association for Information Systems, Article vol. 16, pp. 1-25, 2005.

[22] R. Amit and C. Zott, "Value creation in Ebusiness," Strategic Management Journal, vol. 22, no. 6-7, pp. 493-520, 2001.

[23] P. Timmers, "Business Models for Electronic Markets," Electronic Markets, vol. 8, no. 2, pp. 38, 1998/01/01 1998.

[24] J. Hedman and T. Kalling, "The business model concept: theoretical underpinnings and empirical illustrations," Eur J Inf Syst, vol. 12, no. 1, pp. 4959, 2003.

[25] H. Sjøvaag, "Introducing the Paywall," Journalism Practice, vol. 10, no. 3, pp. 304-322, 2016.

[26] S. Balasubramanian, S. Bhattacharya, and V. V. Krishnan, "Pricing information goods: A strategic analysis of the selling and pay-per-use mechanisms," Marketing Science, vol. 34, no. 2, pp. 218-234, 2015.

[27] J. C. Nunes, "A cognitive model of people's usage estimations," Journal of Marketing Research, vol. 37, no. 4, pp. 397-409, 2000.

[28] E. Kazan, T. Tuunanen, M. Li, H. Ghanbari, and S. Tumbas. "Strategic design towards platform collaboration in the newspaper industry: a design science research study." In Proceedings of the Annual Hawaii International Conference on System Sciences. University of Hawai'i at Manoa, 2020. 